\title{
EVOLUCIÓN DEL MANTO NIVAL EN ELALTO ÁRTICO, NORDENSKIÖLD LAND (SPITSBERGEN, SVALBARD)
}

\author{
Raúl Martín Moreno \\ Department of Sciences and Engineering. Saint Louis University (Madrid Campus) \\ rmarti38@slu.edu \\ Enrique Serrano Cañadas \\ Departamento de Geografía. Universidad de Valladolid \\ serranoe@fyl.uva.es
}

\section{RESUMEN}

Este trabajo expone las características y evolución del manto nival en el Alto Ártico, Spitsbergen, a $78^{\circ} \mathrm{N}$. El manto nival es poco potente y los factores determinantes de su espesor son la topografía y la redistribución por el viento. Su transformación deriva de los procesos de arrastre de nieve y de rehielo que determinan la estructura del manto nival, más simple en los fondos de valle y compleja en las laderas. La transformación primaveral de la nieve es rápida, y dada la presencia de permafrost desaparece lentamente. Durante la primavera y el verano el manto nival se inestabiliza y se produce la mayor frecuencia de aludes. En este periodo se generan los aludes más eficaces desde un punto de vista geomorfológico.

Palabras clave: estructura de la nieve, manto nival, Alto Ártico, Spitsbergen.

\section{ABSTRACT}

In the present work the characteristics and evolution of the snow cover in Spitsbergen, $75^{\circ} \mathrm{N}$ are studied. The main factors determining the snow cover characteristics are the topography and wind redistribution. Snow drift by wind and freeze processes determine the transformation and structure of the snow cover. The snow cover is simpler on the platforms and valley bottom and more complex on slopes. The spring transformation of snow is quick,

Fecha de recepción: junio 2011.

Fecha de aceptación: diciembre 2012. 
and due to the permafrost presence it disappearances slowly. During spring and summer the snow cover is quickly unstabilized and the higher number of snow avalanches are generated. In this period the most efficient geomorphic processes are produced.

Key words: snow structure, snow cover, High-Arctic, Spitsbergen.

\section{INTRODUCCIÓN}

La nieve es un elemento clave de los ambientes árticos y del Alto Ártico y las características del manto nival, su estructura, espesor, distribución y ritmos de fusión, son muy importantes para la correcta comprensión de los fenómenos glaciares, pues la acumulación directa o por aludes repercute en su alimentación. Por el contrario, los mantos nivales delgados favorecen la existencia de permafrost y el desarrollo de los procesos periglaciares intensos, por el menor aislamiento y la consiguiente mayor penetración de la helada en el sustrato. La poca innivación que reciben numerosas regiones del Alto Ártico, donde no hay radiación solar alguna durante casi medio año, influye en los aludes y los procesos geomorfológicos, a partir de la disponibilidad hídrica y su fenología. De este modo, el manto nival dirige la disponibilidad hídrica y, junto al permafrost, el régimen térmico del suelo en laderas, platós y valles durante una parte importante del año. Todo ello tiene consecuencias directas en los procesos y formas geomorfológicas, prioritariamente las periglaciares y, sobre todo, en su intensidad.

El estudio de la nieve en Svalbard se ha centrado prioritariamente en los aludes, con aportaciones relativas tanto a su efectividad geomorfológica (Andrè, 1990a, 1990b; Humlum et al. 2007), como al riesgo en zonas frecuentadas (Humlum, 2002, 2005a, 2005b; Eckerstorfer et al. 2010; Rubensdotter y Eckerstorfer, 2010), al control climático (Hestnes, 2000; Ellehauge, 2003) y a su distribución espacial (Bruland et al. 2001a; Boike, et al. 2003; Winther et al. 2003; Martín Moreno, 2006). Sin embargo se ha prestado poca atención a la fenología del manto nival (Humlum, 2005a) y la relación con la intensidad y dinámica de los procesos periglaciares y nivales, los sistemas morfogenéticos dominantes en la península de Nordenskiöld.

El objetivo de este trabajo se centra en el estudio de la estructura, duración y distribución temporal y altitudinal del manto nival en una región del Alto Ártico como referente para conocer los periodos de disponibilidad hídrica y la importancia del manto nival y su fusión en la morfogénesis.

\section{II. ÁMBITO DE ESTUDIO, NORDENSKIÖLD (SPITSBERGEN, SVALBARD)}

Las áreas de investigación incluidas en el presente estudio se localizan en los valles de Adventdalen y Reindalen, ambos en Nordenskiöld Land, una península situada entre los fiordos de Isj (Isfjorden), al norte, y Bellsounden, al sur, en la isla de Spitsbergen, la más grande del archipiélago de Svalbard (Fig. 1). Pese a su ubicación septentrional, $78^{\circ} \mathrm{N}$, dentro del ámbito del Alto Ártico, la influencia de la corriente cálida del Atlántico Norte mitiga las temperaturas extremas y crean un clima único a estas latitudes. La temperatura media del aire (MAAT) para el periodo de $1975-2000$ fue de $-5.8^{\circ} \mathrm{C}$; mientras que para principios del actual 
Figura 1

MAPA DE LOCALIZACIÓN. A. SITUACIÓN DEL ARCHIPIÉLAGO DE SVALBARD EN EL ÁRTICO. B. SITUACIÓN DE NORDENSKIÖLD LAND EN LA ISLA DE SPITSBERGEN. C. NORDENSKIÖLD LAND CON LA SITUACIÓN DE ADVENTALEN Y REINDALEN

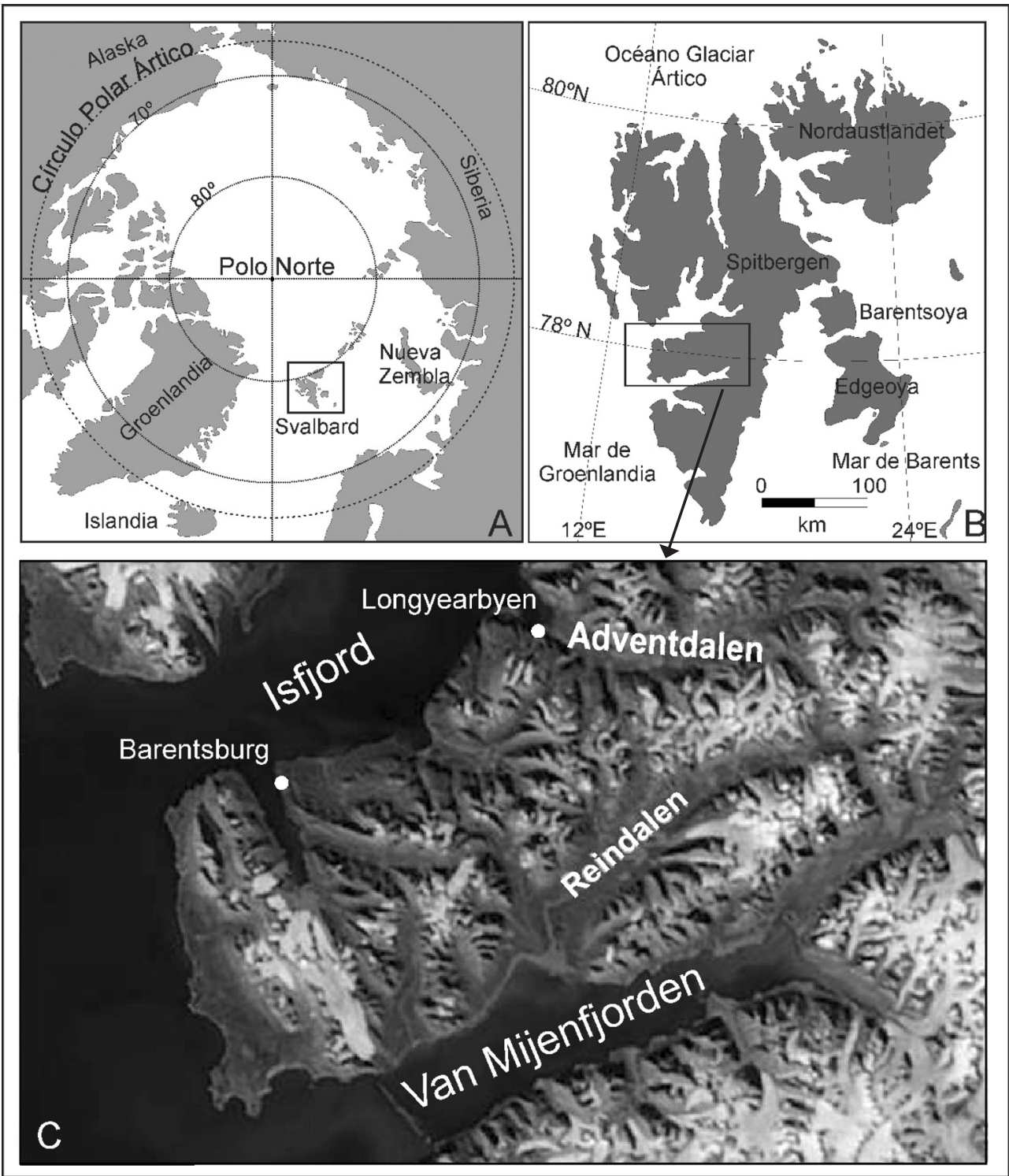

Foto satélite C9 Adventdalen, Landsat 5- Thematic Mapper, 213 / 4, 28 agosto 1986.

siglo se sitúa en $-5^{\circ} \mathrm{C}$. El mes más frío es febrero, con una temperatura media de $-15.2^{\circ} \mathrm{C}$, y el más cálido julio, con $6.2^{\circ} \mathrm{C}$. La precipitación a nivel del mar es de $190 \mathrm{~mm} / \mathrm{a}$, aunque a alti- 
tudes más elevadas son significativamente superiores (Humlum, 2005c; Eckerstorfer et al. 2008). De acuerdo con esta última fuente, la cobertura nival dura desde principios de octubre a principios de junio.

El relieve de las zonas de estudio de Reindalen y Adventdalen está compuesto básicamente por montañas tabulares que forman platós e incisiones de distinta entidad. Los materiales de la zona de estudio están compuestos de una sucesión subhorizontal de areniscas, limolitas y pizarras jurásicas (Grupo Adventalen, Formaciones Helvetiafjellet y Carolinefjellet), que afloran en las laderas, y pizarras, areniscas y limolitas de edad Paleoceno-Eoceno (grupo Van Mijenfjorden) en los platós culminantes y las cumbres (Harland, 1997; Dallmann et al. 2001; Major et al. 2001). Un relieve monoclinal donde el modelado glaciar ha generado sucesivos circos, horns y artesas entre amplias plataformas estructurales. Este sector posee pequeños glaciares alojados en las cabeceras de los valles secundarios, con artesas deglaciadas y amplios complejos morrénicos de la Pequeña Edad del Hielo (Sørbel et al. 2001; Tolggensbakk et al. 2001). Las formas periglaciares constituyen uno de los elementos característicos de Nordenskiöld Land, ocupando los fondos de los valles (pingos, suelos ordenados, polígonos, palsas) y las laderas (tors, glaciares rocosos, lóbulos protalud, lóbulos de gelifluxión, taludes y conos de derrubios, flujos de derrubios). El permafrost es continuo, con espesores máximos de hasta 450 m (Liestø1, 1980; Humlum et al. 2003; Humlum 2005c).

\section{METODOLOGÍA}

El estudio se basa en el examen de fotografías sucesivas y el trabajo de campo. El análisis en el campo ha consistido en el estudio de perfiles de nieve con descripción de la organización interna, la estratificación y la potencia del manto nival para conocer la estructura interna y evolución del manto nival (Fietz et al. 2009) en los valles de Adventalen y Reindalen. Los trabajos de campo se han llevado a cabo durante una estación cálida, julio de 2002, un periodo frío, marzo y abril de 2004, y una época de deshielo, junio de 2010. Debido a la lejanía de zonas habitadas y lo remoto del área de estudio, no ha sido posible realizar campañas continuas y más frecuentes.

El estudio de la distribución espacial con la altitud se ha realizado sobre imágenes de Adventalen de los años 2000-2004, obtenidas dos veces al mes y disponibles en la University of Svalbard (UNIS). Esta metodología ha sido aplicada al estudio de la nieve en medios árticos (Christiansen, 2001) para conocer la evolución del manto nival. En este caso se ha aplicado a la fusión nival, mediante la estimación del periodo de fusión del manto continuo, considerado cuando la nieve cubre en su totalidad el suelo, y la desaparición del manto discontinuo, considerado cuando la nieve no cubre la totalidad del suelo, entre el nivel del mar y $\operatorname{los} 850 \mathrm{~m}$.

\section{DISTRIBUCIÓN Y CARACTERÍSTICAS DE LA NIEVE EN LOS VALLES DE ADVENTDALEN Y REINDALEN}

La innivación en los valles de Adventdalen y Reindalen es menor que en el resto de las áreas contiguas de Spitsbergen debido principalmente a su posición a favor de los vientos dominantes de dirección E-W. Este fenómeno explica también su menor superficie glaciada 
frente a las otras regiones del archipiélago (ver Fig. 1C). Los datos climáticos de la UNIS y las fotografías aéreas confirman la predominancia de vientos con esta dirección. Las agujas de hielo y nieve observadas durante los trabajos de campo en el invierno, la existencia de extensas áreas sin nieve a barlovento, y la localización de los ventisqueros a sotavento, esto es al W, señalan la importancia del viento de dirección dominante del E en la distribución de la nieve durante el invierno, circulando intensa y regularmente y barriendo los fondos de los valles. En el mes de enero la nieve cubre el fondo de valle en su totalidad, mientras que en las áreas vecinas (como las montañas, platós y valles tributarios) el manto nival es ya continuo desde noviembre. El máximo de acumulación nival tiene lugar en el mes de abril, cuando se alcanza una mayor profundidad y una distribución más regular, tanto en Adventalen como en las áreas vecinas (registro meteorológico de la UNIS y Humlum, com. pers.).

Las características nivales de Spitsbergen están marcadas por tres importantes variables: la radiación solar recibida (que determina la temperatura y por tanto la fusión nival), la topografía y los regímenes del viento. El déficit radiactivo y las consiguientes bajas temperaturas durante la larga noche polar implican densidades bajas, entre $273 \mathrm{~kg} / \mathrm{m}^{3}$ y $310 \mathrm{~kg} / \mathrm{m}^{3}$ (Grzés y Sobota, 2000; Liston y Sturm, 2002) por la lenta transformación de la nieve, comparado con las regiones alpinas. Además, no existen variaciones de densidad significativas entre los fondos de valle y las áreas elevadas (Sand et al. 2003). En segundo lugar, la topografía y el relieve controlan en gran medida la distribución de la nieve en el ártico (Ming-ko Woo,

Figura 2

BANDEADO DE LA NIEVE EN EL FONDO DE VALLE DE REINDALEN

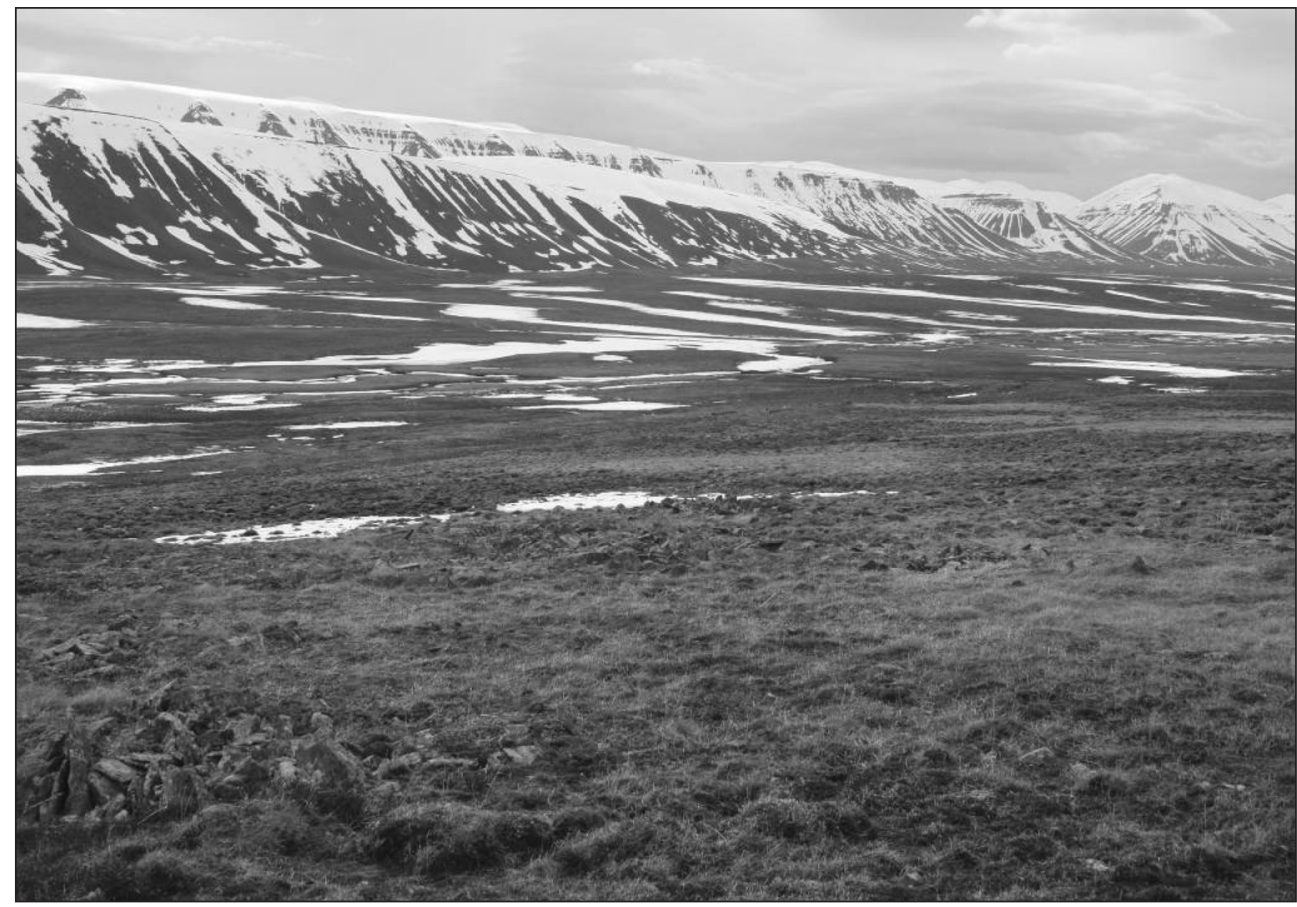


1998). La amplitud y la topografía suave de los valles de Adventdalen y Reindalen limita la formación de ventisqueros a las irregularidades del sustrato. Durante el periodo de desaparición de la nieve los neveros quedan alojados en las depresiones de los arroyos perpendiculares al río principal (Fig. 2). Los sondeos realizados muestran que la potencia de la nieve es directamente proporcional a la profundidad de los valles por los que circulan estos pequeños ríos. El resultado es un paisaje característico durante la época de deshielo, con un fondo de valle bandeado por los neveros alargados en dirección N-S, transversales al río principal. La acumulación de nieve es mayor en la desembocadura de estos valles tributarios, donde la nieve que circula por el valle en dirección E-W queda atrapada en grandes ventisqueros colgados sobre Reindalen, con un espesor de nieve acumulado de varios metros (Fig. 3). En los fondos de los valles del Alto Ártico existe una correlación entre la acumulación de la nieve y la tipología de la vegetación (Bruland, 2002). Si bien en las áreas de estudio la vegetación es muy escasa, ubicada en las zonas oro Cassiope tetragona y oro Dryas octopelata, con formaciones vegetales caracterizadas por la tundra musgosa y liquénica con retazos dispersos de brezales rastreros (Rønning, 1996), existen algunos casos relevantes. Por ejemplo, cuando hay una gran densidad de montículos de hierba o thufurs, la nieve queda atrapada y se registra una mayor acumulación (Fig. 4A).

La topografía suave y la ausencia de vegetación de la zona de estudio facilitan la libre circulación del viento sobre la superficie, que moviliza y transporta la nieve, acumulándola en ventisqueros a sotavento. Por el contrario, en las zonas más expuestas la presencia de nieve

Figura 3

VENTISQUERO FORMADO EN UN PEQUEÑO VALLE TRIBUTARIO A REINDALEN

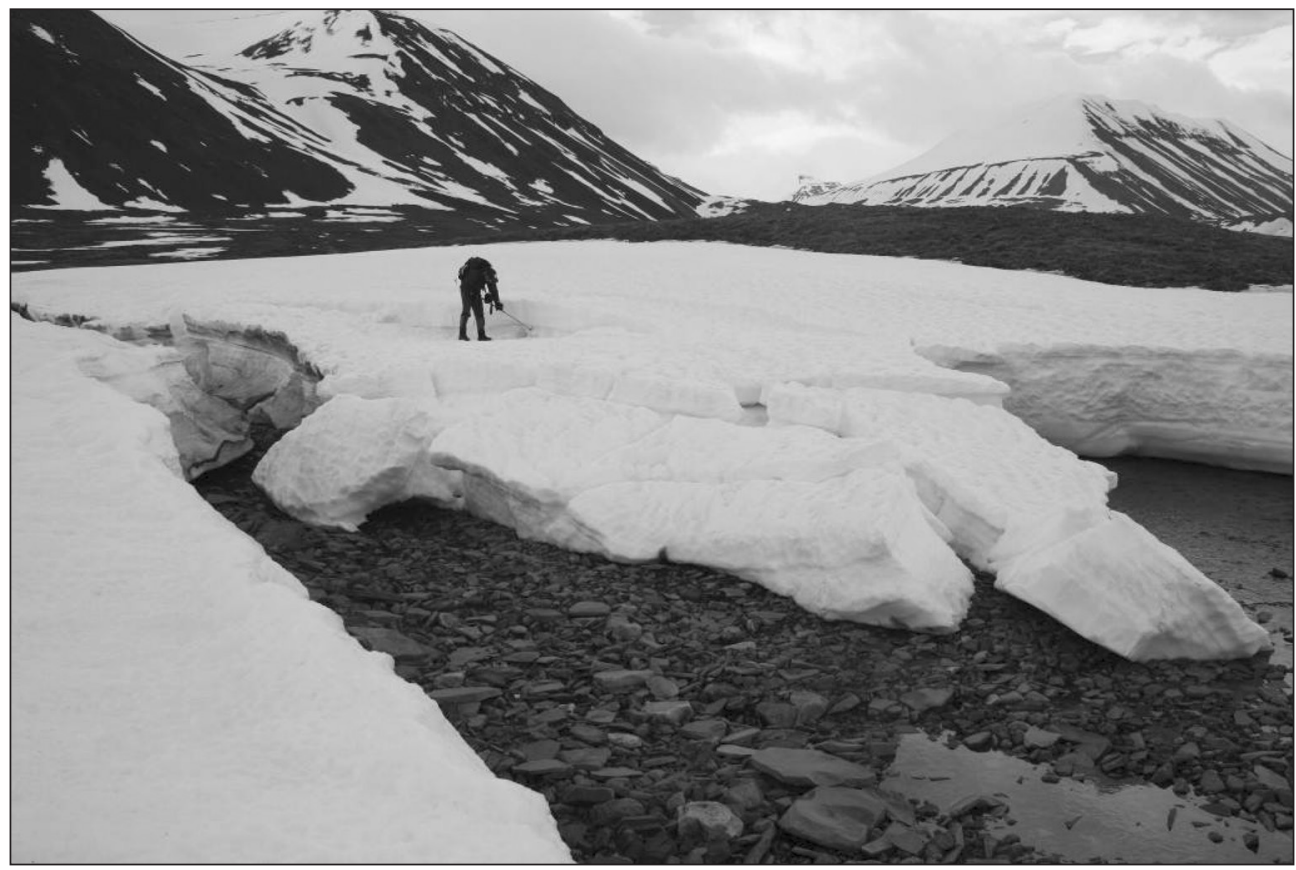


Figura 4

A, DESARROLLO DE HUMMOCKS AL PIE DE LAS LADERAS CON NEVEROS (TVERRDALEN). B, NICHO DE NIVACIÓN Y NEVERO EN LADERA (BJØRNDALEN)
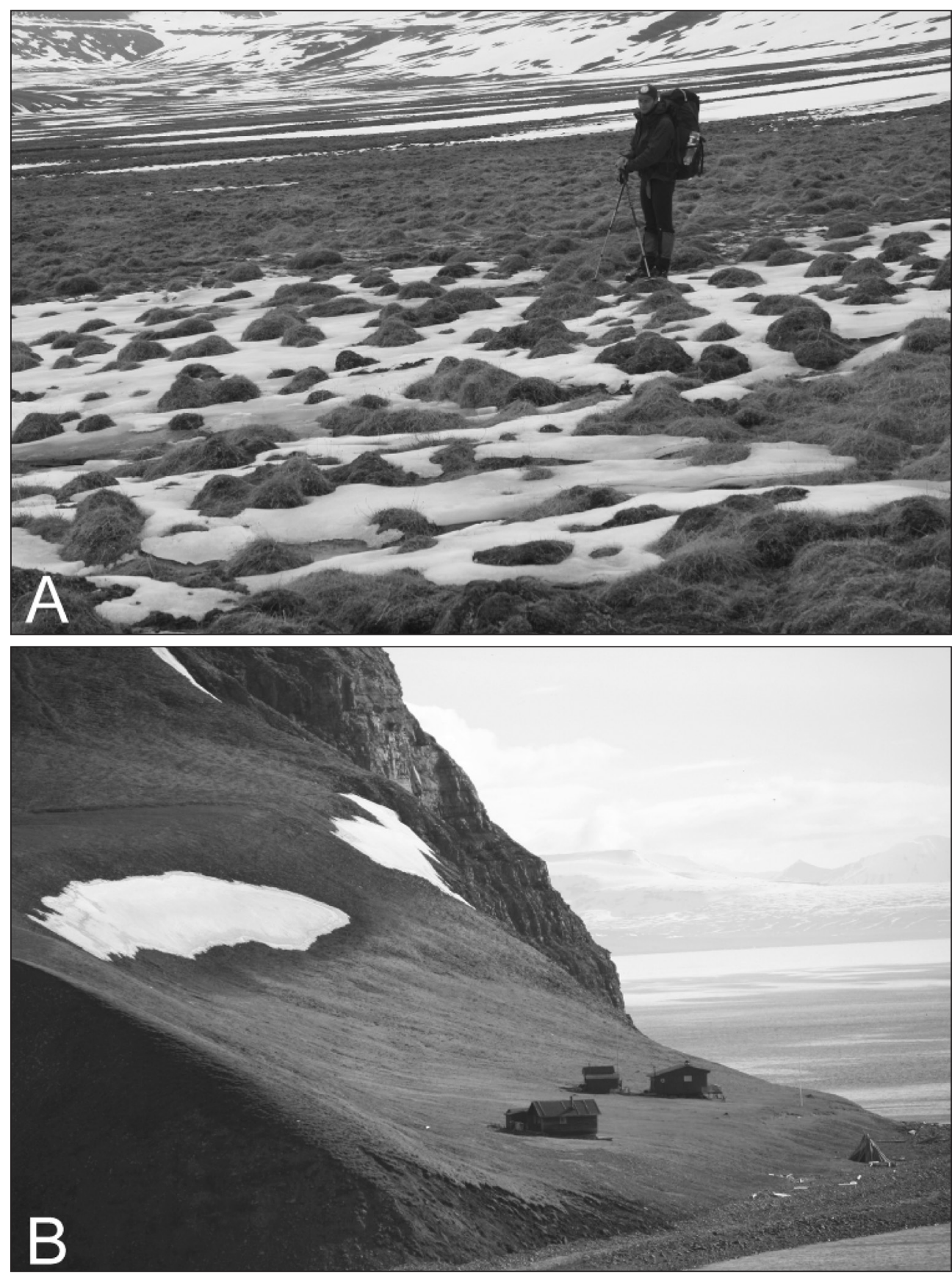


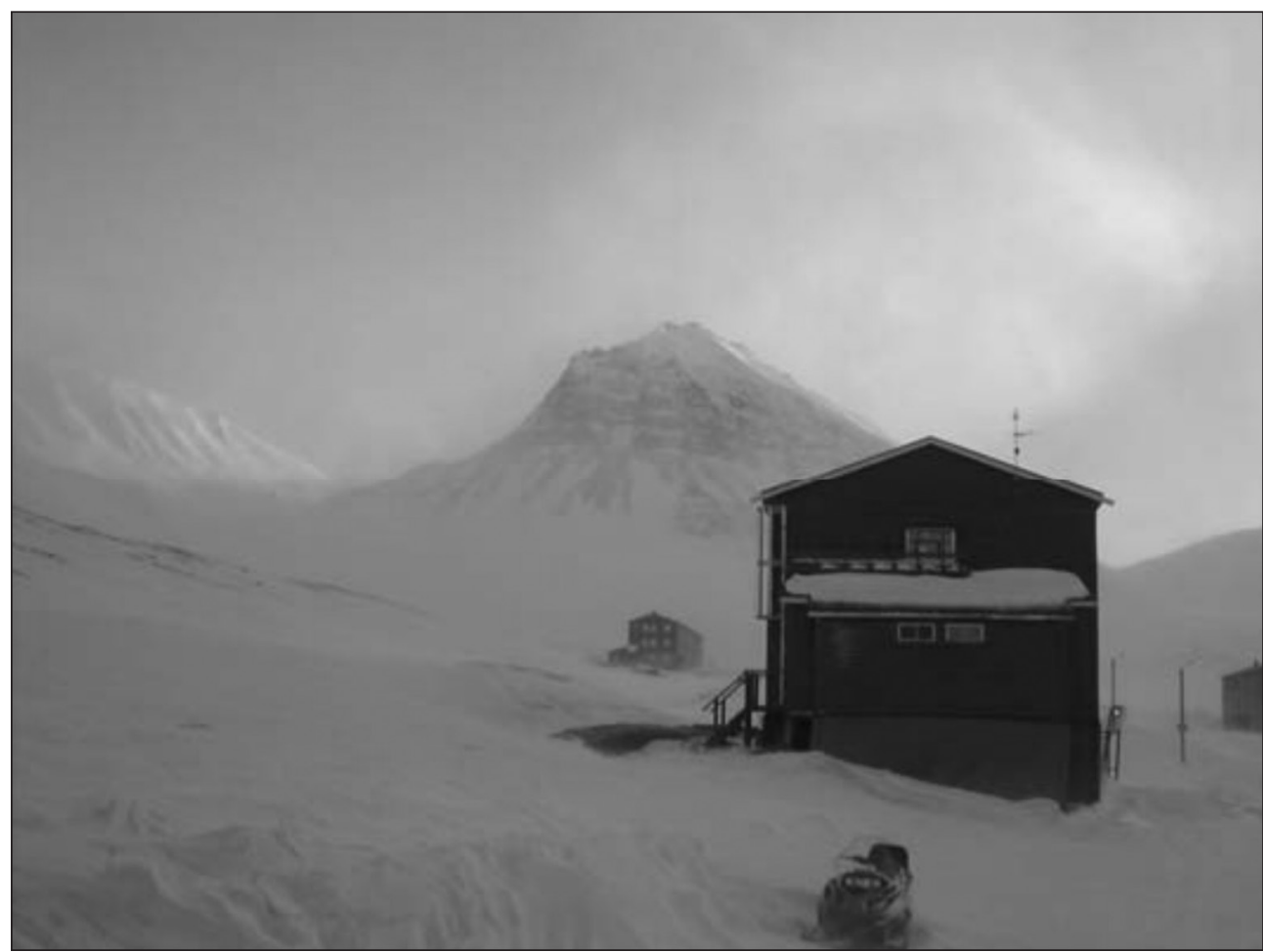

puede llegar a ser completamente nula o muy escasa durante gran parte de la estación fría. Finalmente, el arrastre de la nieve por el viento (Fig. 5) está condicionado por las características físicas de ésta, dependientes de la temperatura y la humedad relativa, y relacionadas con el grado de cohesión, no del tamaño de las partículas de nieve, de modo que se desplaza y redistribuye por saltación y suspensión (Schmidt, 1981; Pomeroy y Gray, 1990).

En 2004, durante la estación fría, la cubierta nival pasó de 1 metro de espesor a su completa desaparición en unas horas. Durante largos periodos con ausencia de precipitación nival directa, la dirección y la intensidad del viento sobre las laderas de las montañas y el fondo de los valles implican pérdidas de nieve muy acentuadas. La transformación invernal de la nieve bajo una temperatura baja y uniforme $\left(<0^{\circ}\right)$ implica cambios menores y densidades bajas que caracterizan la nieve invernal en estas latitudes. El viento a velocidades de tan sólo $0.07 \mathrm{~m} \mathrm{~s}^{-1}$ puede llegar a desplazar una ligera capa de nieve polvo (Male, 1980), y cuando la velocidad se incrementa las partículas de nieve se desplazan en suspensión (Jaedicke y Sadnvik, 2002). En las áreas de estudio de Spitsbergen la velocidad del viento es máxima durante el invierno, con velocidades de hasta $18 \mathrm{~m} \mathrm{~s}^{-1}$ (Boike et al. 2003), justo cuando la densidad es menor, y los procesos de saltación y suspensión adquieren una mayor relevancia. Los resultados obtenidos durante eventos de fuerte viento muestran valores diarios de transporte de nieve 
de $\sim 1000 \mathrm{~kg} / \mathrm{m}^{2}$ con vientos de entre 4.8 y $5.0 \mathrm{~m} / \mathrm{s}$; con velocidades menores, en torno a 3.8 y $4.2 \mathrm{~m} / \mathrm{s}$ el transporte medio es de $300-350 \mathrm{~kg} / \mathrm{m}^{2}$ (Grzés y Sobota, 2000). De este modo, en Adventdalen y Reindalen el viento desplaza la nieve numerosas veces durante el invierno y su redistribución es clave para comprender el manto nival (Grzés y Sobota, 2000; Bruland et al. 2001a; Sturm et al. 2001; Whinter et al. 2003).

\section{LA ESTRUCTURA INTERNA Y LA EVOLUCIÓN DEL MANTO NIVAL EN ADVENTADALEN Y REINDALEN}

La estructura del manto nival en el fondo de los valles de Adventdalen y Reindalen en invierno es muy simple (Fig. 6), y está fundamentalmente compuesta por:

(i) un estrato inferior de nieve helada, estable y permanente. Este estrato inferior se forma a principios de la estación fría, bien por su exposición a fuertes vientos, que transforman la nieve en una costra endurecida hasta convertirla en hielo, o por la congelación masiva del agua de lluvia. Este fenómeno alcanzó su máximo exponente en el mes de enero de 2008, cuando la temperatura del aire ascendió de manera repentina hasta los $5.8^{\circ} \mathrm{C}$ a nivel del mar y posteriormente se registraron $11 \mathrm{~mm}$ de lluvia (cuando la media de todo el mes son $15 \mathrm{~mm}$ ). Tan sólo 24 horas después la temperatura descendió hasta $\operatorname{los}-14^{\circ} \mathrm{C}$, lo que generó un estrato de hielo de hasta 10 $\mathrm{cm}$ (Eckerstorfer et al. 2008).

(ii) un estrato superior de nieve inestable, de 40-60 $\mathrm{cms}$ de espesor, que puede ser transportada sucesivas veces por el viento.

La estratigrafía de la nieve es más compleja en los ventisqueros y en las cornisas, con diferentes capas de distinta naturaleza (Fig. 6). La estructura interna y la estratificación se complican con la evolución estacional del manto nival:

- Durante el invierno los copos de nieve se erosionan y se desarrollan cristales de hielo internos (tipo depth hoar) y horizontes de rehielo en profundidad, que han sido descritos también en latitudes sub-antárticas, como la Isla de Livingston a $62^{\circ} \mathrm{S}$ (Vilaplana y Pallàs, 1993). Los espesores medios de la nieve son difíciles de estimar durante la estación fría, debido a la gran variabilidad espacial antes descrita. Mediante técnicas de teledetección se ha calculado la cantidad de nieve acumulada en áreas cercanas a los valles estudiados. En Ny Ålesund, también en la isla de Spitsbergen, más al norte $\left(80^{\circ} \mathrm{N}\right)$ y con mayor precipitación $(\sim 400 \mathrm{~mm})$, se han estimado espesores medios de $70 \mathrm{~cm}$ (Bruland et al. 2001b) y en los glaciares de Drønbreen y Blekumbreen, de 30 cm durante el invierno (Jaedicke y Sadnvik, 2002).

- Al final de la estación fría, con el fin de la larga noche polar y la llegada de temperaturas positivas y un gradiente térmico dentro del paquete nival, se inicia la transformación del manto nival y su desaparición desde la superficie. La estructura cambia, con la aparición de una costra de hielo superficial (sun crust) de apenas $1 \mathrm{~cm}$. de espesor, la disminución del paquete de nieve, la estructura granular («huevas de caviar») y la génesis de un estrato basal de hielo impermeable, generado durante las primeras fases de fusión nival, junto a la presencia de agua líquida, lo que desencadena numerosos procesos relevantes. A medida que el paquete nival recibe más calor, la densidad de la nieve se incrementa rápidamente, alcanzando valores medios de $445 \mathrm{~kg} / \mathrm{m}^{3}$ al 
Figura 6

ESTRATIGRAFÍA DEL MANTO NIVAL EN OTOÑO, INVIERNO Y PRIMAVERA MOSTRANDO LA EVOLUCIÓN DE LA ESTRUCTURA INTERNA EN REINDALEN
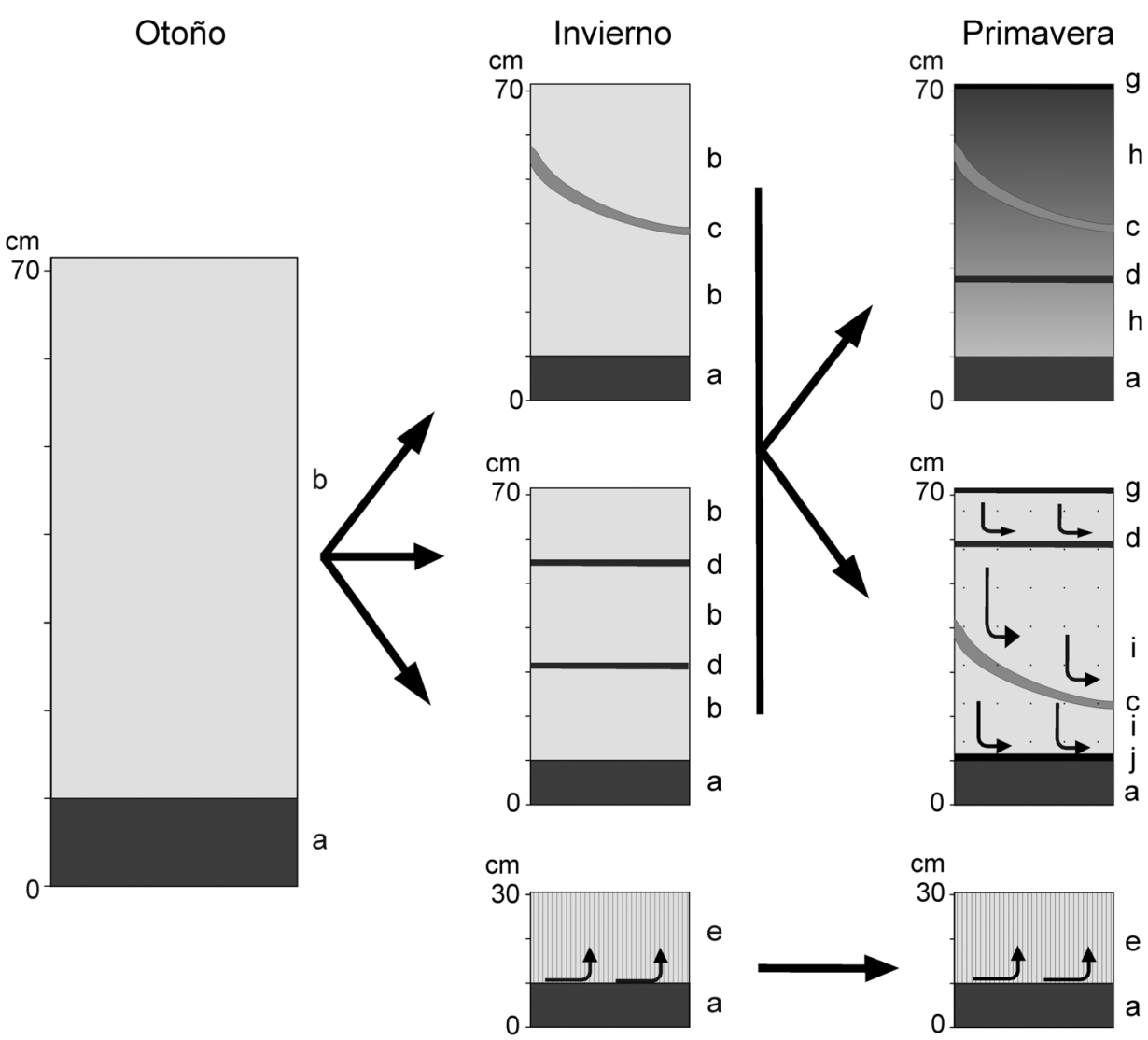

a, nieve congelada. b, manto nival, de caída y venteada. $c$, placas de nieve venteada. $d$, horizontes de rehielo (depth hoar). e, icing. f, incremento de densidad. g, costra de rehielo superficial (sun crust). h, Incremento de densidad nival. i, hielo granular. j, estrato basal de rehielo.

principio de la estación de deshielo (Boike et al. 2003). La metamorfosis de fusión genera aglomerados de grandes granos de hielo redondeados (2-3 mm) y sin cohesión y agua líquida que circula por el paquete nival. El agua procedente de las lluvias o de la fusión nival percola hacia niveles inferiores y la influencia de la onda térmica procedente del permafrost subyacente enfría la porción inferior del manto de nieve, de modo que el agua se congela aunque la temperatura exterior se mantenga regular sobre los $0^{\circ} \mathrm{C}$. De este modo se genera un estrato basal de rehielo, muy común en las regiones árticas (Gerland et al. 1999; Bruland et al. 2001b). Además, los intensos vientos generan placas de viento de nieve más densa en las laderas a sotavento. 
Los procesos y los ritmos de deshielo del manto nival son fundamentales para el desarrollo de procesos nivales y periglaciares derivados de la protección o desprotección del suelo por el manto nival y su influencia térmica, o de la disponibilidad hídrica para los mismos. Pero los ritmos de desaparición del manto nival cambian en función de la altitud (Tabla 1; Fig. 7), generando también variaciones temporales de los procesos geomorfológicos con la altitud. El análisis de la pérdida del manto nival permite apreciar comportamientos diferenciado por altitudes:

0-100 m. En el fondo de valle la cobertura nival es muy delgada durante todo el invierno, siempre inferior a los $35 \mathrm{cms}$ (Chirstiansen y Humlum, 2008), salvo en áreas muy localizadas donde el viento acumula mayores espesores. La nieve permanece irregularmente a partir de octubre y el máximo espesor se alcanza en los meses de febrero, marzo y abril, con los mínimos a mediados de diciembre y finales de enero. El manto continuo permanece con un espesor de más de $10 \mathrm{cms}$ entre mediados de noviembre y finales de abril (5 meses), iniciándose una lenta fusión, con un manto discontinuo que perdura dos meses. Esta altitud permanece libre de nieve cinco meses al año.

100-400 m. Permanece libre de nieve dos meses y medio (80 días). El manto se restablece a principios octubre y permanece continuo más de 6 meses. En estos 300 metros el manto continuo desaparece en un mes (mitad de abril a mitad de mayo), y se inicia una lenta fusión del manto discontinuo durante mes y medio (de mediados mayo a inicios de julio, cuando se produce la fusión total).

400-550 m. Desde septiembre el manto nival es continuo. Su fusión primaveral es lenta, pasando de un manto nival continuo a discontinuo en 15-45 días, mientras que el manto discontinuo perdura más de dos meses (mediados de mayo a mediados julio). Es el área con mas amplitud de tiempo con un manto nival discontinuo, y por tanto donde los procesos nivales y periglaciares son más eficaces por la disponibilidad hídrica y la influencia atmosférica sobre la superficie del suelo. Sólo durante dos meses y medio permanece libre de nieve.

550-750 m. Es el último sector con fusión total del manto nival, permaneciendo sin nieve 40 días. La fusión del manto es rápida, pasando a discontinuo en 10-15 días. Más lenta y desigual es la desaparición del manto nival discontinuo, que dura un promedio de 55 días, siempre más de un mes.

$>750 \mathrm{~m}$. Por encima de $725 \mathrm{~m}$ (600-850) siempre existen neveros. El paso del manto continuo a discontinuo se produce en 30 días, mas lentamente que en altitudes inferiores, sin desaparecer nunca el manto discontinuo y los neveros. La recuperación es rápida, con el primer temporal de septiembre.

Tabla 1

PERMANENCIA DE LA NIEVE Y PERIODOS DE FUSIÓN EN ADVENTDALEN

\begin{tabular}{|c|c|c|c|c|}
\hline \multirow{2}{*}{$\begin{array}{l}\text { Altitud } \\
\text { m s.n.m. }\end{array}$} & \multirow{2}{*}{$\begin{array}{c}\text { Libre de nieve } \\
\text { Días }\end{array}$} & \multicolumn{2}{|c|}{ Manto nival discontinuo } & \multirow{2}{*}{$\begin{array}{c}\text { Manto nival continuo } \\
\text { Días }\end{array}$} \\
\hline & & Días de fusión & $\begin{array}{r}\text { Periodo } \\
\end{array}$ & \\
\hline $600-850$ & 0 & 60 & Julio/agosto & 300 \\
\hline $550-750$ & 40 & 45 & FinJulio/prin.Septiembre & 280 \\
\hline $400-550$ & 60 & 55 & $1 / 2$ mayo/ $1 / 2$ junio & 250 \\
\hline $100-400$ & 80 & 80 & $1 / 2$ mayo/principio junio & 205 \\
\hline $0-100$ & 150 & 60 & Fin abril/fin mayo & 150 \\
\hline
\end{tabular}


Adventdalen se caracteriza por la rápida fusión del manto nival, que pasa de continuo a discontinuo y desaparece en 40 días de promedio al nivel del mar, y 35 días a 700 metros. La fusión total afecta a altitudes entre 0 y $750 \mathrm{~m}$, con un retraso en altitud en el periodo de máxima actividad nival que pasa de abril-junio en el nivel del mar, a julio-agosto por encima de 700 metros. Se puede estimar el promedio de retraso de los procesos periglaciares y nivales con la altitud en $250 \mathrm{~m} / \mathrm{mes}$, alargándose a 3 meses el periodo de fusión entre los 0-700 metros, con aportación permanente de agua a las laderas y fondos de valle. El retraso en la desaparición de la nieve en Spitsbergen, iniciado a finales de abril, se produce debido al tiempo requerido para calentar el manto de nieve. Bruland et al. (2001b) observaron que el mayor deshielo se produce unos días más tarde de empezar el periodo de ablación, por una respuesta muy lenta ante el ascenso térmico, dado el mayor requerimiento energético para alcanzar el punto de fusión, al menos en comparación con las áreas alpinas. Tal es así que, al comienzo del periodo de deshielo, casi la totalidad de la energía es absorbida por la nieve, de forma que aún con tasas de radiación elevadas, las temperaturas siguen manteniéndose bajas. El permafrost, que genera una onda de frío subyacente, y el congelamiento de las capas inferiores del manto nival implican la necesidad de mayor radiación solar y el consiguiente retraso del deshielo completo. Además, posibilita la circulación superficial de agua y la saturación de la capa activa. De este modo genera el periodo de mayor eficacia morfogenética asociado a las aguas de fusión (torrencial y fluvial) y la dinámica de laderas (periglaciar y nival). Es el periodo más importante en la transferencia de sedimentos, asociado a la nivación y aportación hídrica por fusión del manto nival, coincidente con periodos de amplio gradiente térmico diurno nocturno, que favorecen procesos de gelifluxión, crioclastia, ordenación, levantamiento e icing en las laderas y fondos de valle. Pero este periodo se escalona en el tiempo con la altitud y, como hemos vito, es más breve a partir de los $400 \mathrm{~m}$ de altitud.

Debido a la heterogénea distribución de la nieve sobre la superficie por el efecto del viento, su desaparición es también desigual en Adventdalen y Reindalen. En las orientaciones norte la cobertera nival es ligeramente mayor que en la solana, si bien las variaciones no son tan significativas como ocurre en las montañas de las latitudes templadas y sub-polares. Sí lo son, por el contrario, entre las vertientes orientadas al W respecto a las del E por el factor de barrido y acumulación de nieve en función de los vientos dominantes, que prevalece sobre los de umbría y solana. En topografías más vigorosas, las diferencias entre la umbría y la solana es más acusada, como muestran los glaciares más pequeños del área estudiada (Evans y Cox, 2010). La posición baja del sol, aún durante el periodo de deshielo, y su movimiento circular en el cielo (responsable de unas temperaturas homogéneas en todas las orientaciones), contribuyen a este significativo fenómeno. En el periodo con manto discontinuo a distintas altitudes es en los neveros donde se concentra la actividad morfogenéticas ligada a la nieve. En los neveros ubicados en topografías horizontales, las aguas de fusión empapan y saturan la nieve, lo que produce importantes encharcamientos supranivales, de hasta $50 \mathrm{~cm}$. En los neveros situados en pendiente, el agua de fusión circula bien por encima de la capa basal helada, bien acumulándose hasta hacerse inestable y desencadenar pequeños aludes y flujos de nieve saturada que se desplaza sobre el hielo. Por el contrario, la capa basal congelada y la nula circulación basal, impiden procesos subnivales. La circulación de las aguas de fusión sobre la nieve favorece la presencia y desarrollo de ciertas formas y procesos pronivales como montículos de hierba (thufurs) y lóbulos de solifluxión (Fig. 4B). 
La configuración otoñal y la desaparición estival del manto nival en Reindalen y Adventdalen rigen los procesos geomorfológicos más eficaces con retrasos en la cadencia de los procesos con la altitud. Pero las causas son las mismas, partiendo de una noche polar y un día estival que señala los ritmos energéticos. En el Alto Ártico el derretimiento del manto nival se generan por sublimación y fusión. La sublimación tiene lugar cuando la radiación solar es muy intensa (sólo durante la estación diurna), o por la acción del viento seco sobre la nieve (Bintanja, 1998; mencionado en Jaedicke y Sadnvik, 2002), durante todo el año. La sublimación ocasiona pérdidas entre el 5 y el 50\% (Liston y Sturm, 2002), mientras el resto de las pérdidas (entre el $50 \%$ y el 95\%) tienen lugar por fusión. La radiación solar y los flujos de radiación primaveral y estival son, pues, responsables del derretimiento nival en Spitsbergen (Woo et al. 1983; Young et al. 1997; Harding y Lloyd, 1998). El balance de radiación invernal está dominado por las pérdidas al espacio de radiación de onda larga, mientras que prácticamente no existe una recepción de radiación de onda corta en todo el invierno, pues el sol está por debajo del horizonte durante casi cinco meses. No obstante, por la posición geográfica de las Svalbard respecto a la Corriente del Atlántico Norte, en cualquier momento del invierno la temperatura del aire puede superar los $0^{\circ} \mathrm{C}$ y producirse precipitaciones líquidas (como sucedió en 2008). Pese a este incremento térmico puntual, la superficie de la nieve no alcanza la temperatura de fusión, debido a que el permafrost la mantiene muy fría, y congela la lluvia rápidamente al entrar en contacto con el sustrato, si bien puede transformar las capas superiores del manto nival y generar aludes de fusión por sobresaturación. En Longyearbyen, la totalidad de las carreteras de la ciudad permanecen heladas durante todo el invierno, incluso con temperaturas superiores a $\operatorname{los} 0^{\circ} \mathrm{C}$, menos en los puentes, por donde circula aire por debajo y no existe permafrost, de modo que el hielo y la nieve desaparecen durante las invasiones de aire cálido, dejando al descubierto el pavimento.

EVOLUCIÓN DEL MANTO NIVAL EN ADVENTDALEN CON LAALTITUD

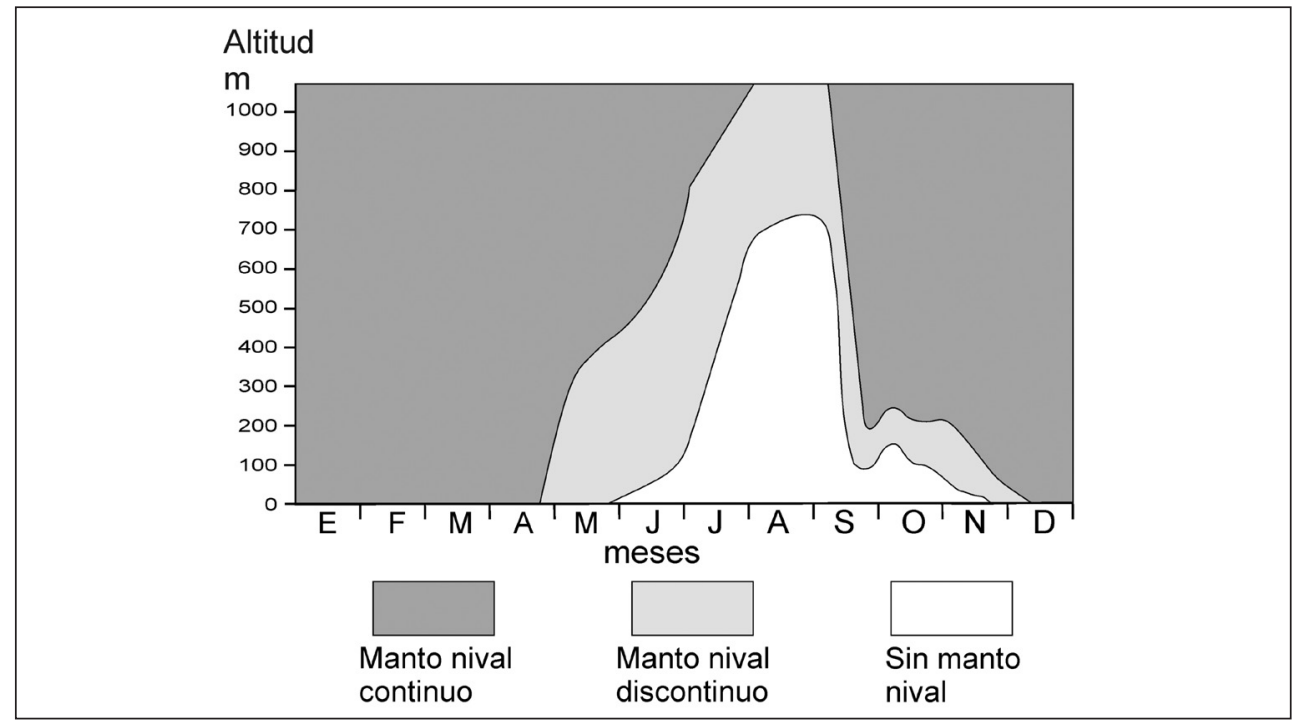


La desaparición total del manto nival en los medios árticos tiene lugar en un periodo muy corto de tiempo, de tan sólo tres semanas (Whinter et al. 1999; 2003), lo que se corrobora en la zona estudiada (4-5 semanas). En las áreas de menor acumulación de nieve, como en las zonas bajas y alejadas de las laderas de Adventdalen y Reindalen puede conllevar incluso menos tiempo, aunque se compensa por la persistencia de los ventisqueros, la acción del permafrost y los procesos de icing, que implican la continuidad del manto nival discontinuo o de hielo en el suelo.

\section{LOS ALUDES EN LAS ÁREAS DE ADVENTDALEN Y REINDALEN}

Los aludes en el Alto Ártico no han sido considerados tradicionalmente como un proceso nival y geomorfológico de primer orden, debido a varios factores: la escasa precipitación nival directa de las regiones árticas, la homogeneidad térmica durante la larga noche polar, los moderados desniveles y pendientes, y la menor presencia e interacción del ser humano en este medio. Es en la actualidad, por lo menos si nos atenemos al entorno de Longyearbyen, cuando los aludes empiezan a cobrar interés (Humlum, 2005a, 2005b, Eckerstorfer et al. 2010; Rubensdotter y Eckerstorfer, 2010). La principal razón estriba en el progresivo aumento de las actividades antrópicas en un medio hasta hace poco completamente deshabitado. La primera mención histórica sobre catástrofes por aludes en Spitsbergen data de junio de 1953, cuando un alud de nieve húmeda mató a tres personas e hirió a otras 30, y en los últimos años se han producido varios accidentes mortales en las proximidades de Longyearbyen (Instanes et al., 2004; Eckerstorfer y Christiansen, 2010).

En Spitsbergen los aludes son un fenómeno frecuente por su relieve favorable (amplios platós que benefician la acumulación de nieve en sus cornisas), la ausencia de vegetación y la presencia de un manto nival continuo durante gran parte del año (Eckerstorfer et al. 2008). En Adventdalen y Reindalen existe un desarrollo potencial de aludes de placa, de pérdida de nieve o primavera, y por desprendimientos de cornisas, estos últimos los más frecuentes en el entorno de Longyearbyen (Humlum, 2005b; Eckerstorfer et al. 2008). Estudios y observaciones recientes en el entorno de Longyearbyen muestran que estos son más frecuentes en los valles laterales (Todalen, Endalen, Bolterdalen, Tverrdalen), que en los principales (Adventalen o Reindalen). Comúnmente, los aludes procedentes de las cornisas y laderas, no alcanzan el fondo de los valles, pero su efectividad geomorfológica es relevante (Fig. 8A). La práctica totalidad de las laderas en las cercanías de Longyearbyen presenta canales de aludes, principalmente activos durante la estación de deshielo a partir del colapso de las cornisas de nieve que se desarrollan a sotavento (Fig. 8B). Si atendemos a la frecuencia y fenología de los aludes, existen dos fases principales de aludes, con connotaciones geomorfológicas diferenciadas:

(i) Aludes de invierno: Los aludes invernales y de principio de la primavera representan el $40 \%$ de los aludes en el entorno de valles secundarios como Todalen (Eckerstorfer et al. 2010; Rubensdotter y Eckerstorfer, 2010). En este periodo se generan aludes de placa, por sobre-acumulación y transformación del manto nival, y aludes de cornisa, asociados también a la sobre-acumulación por el viento y a la gravedad, que suceden durante toda la estación invernal. La efectividad de los aludes de invierno se traduce en la transferencia de nieve desde las plataformas hacia las laderas y fondos de valle, con consecuencias en la 
Figura 8

DIFERENTES TIPOS DE ALUDES EN NORDENSKIÖLD LAND. A, ALUDES DE CORNISA, JUNIO DE 2010, BJØRDALEN.

B, CORNISAS DE NIEVE EN LA PLATAFORMA MEDIA Y CANALES DE ALUDES EN ORIENTACIÓN NW SOBRE LONGYEARBYEN. C. ALUDES DE CORNISA EN LONGYEARDALEN. D, ALUDES DE FONDO EN LAS LADERAS ORIENTALES DE TVERRDALEN, JUNIO DE 2010. E, ALUDES DE NIEVE SATURADA (SLUSH) EN BOLTERDALEN, ORIENTADO AL NE.

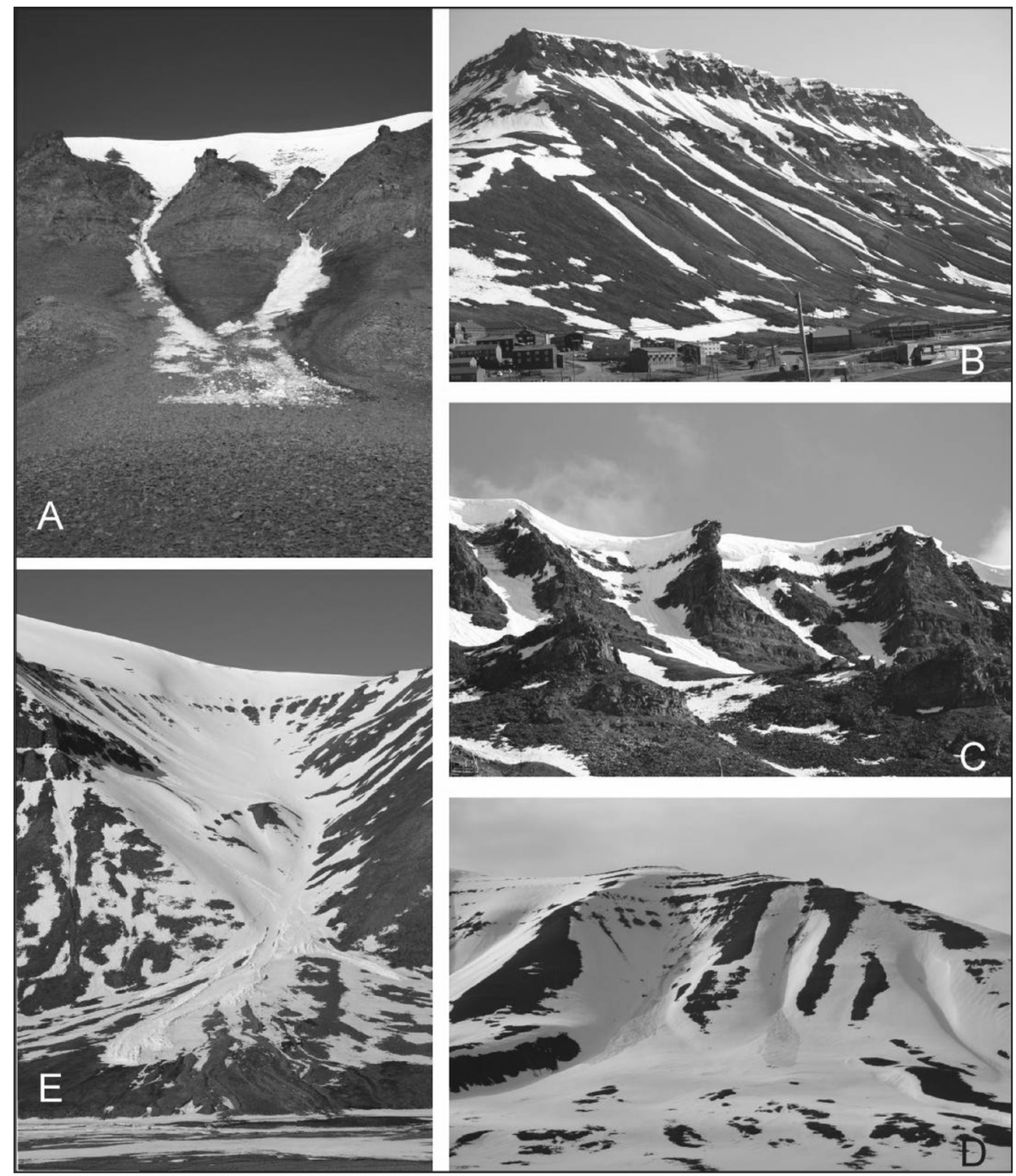

estratigrafía del manto nival en las laderas. Estos aludes, pues, carecen de significado geomorfológico, sin embargo son los responsables del alargamiento de los periodos de fusión en las laderas y fondos de valles, con mantos nivales discontinuos que retrasan su fusión. Su importancia morfogenética deriva de propiciar procesos nivales en las porciones medias y bajas de las laderas durante la primavera y verano, no asociados directamente a la diná- 
mica de los aludes. (ii) Aludes de primavera: La mayor frecuencia de estos aludes sucede en mayo y junio, cuando las temperaturas ascienden por encima de $0^{\circ} \mathrm{C}$ y la radiación solar directa inestabiliza el manto nival (Humlum et al. 2007; Ekerstorfer et al. 2008; 2010). En Todalen, durante el periodo frío de 2008/2009, el 60\% de los aludes se generaron entre mediados de marzo y mediados de mayo (Erckerstofen et al. 2010), periodo que coincide con las laderas aún cubiertas por la nieve. Los aludes de este periodo son aludes de fusión (Fig. $8 \mathrm{D}, 8 \mathrm{E})$, generalmente relacionados con el inicio del incremento térmico y la presencia de precipitaciones líquidas, y aludes de cornisa, cuya actividad se alarga hasta el verano. Los primeros desplazan una gran cantidad de nieve que se aloja en las zonas bajas, y no tienen consecuencias geomorfológicas directas, mas allá de los procesos nivales ligados a su fusión. Los aludes de cornisa sí tienen importancia geomorfológica, pues incorporan derrubios de tamaño variable procedentes de la pared, transportan materiales y los acumulación en conos de derrubios mixtos, así como por la agradación del permafrost y la génesis de glaciares rocosos (Humlum, 2005a; 2005c; Humlum et al. 2007). En las laderas libres de nieve, los aludes de cornisa redistribuyen los sedimentos no consolidados acumulados por flujos de derrubios, gravedad y otros procesos de ladera. A pesar de su alta efectividad geomorfológica por incidir sobre laderas sin nivación, también son los menos frecuentes (20\% de los aludes) y se concentran en las laderas más bajas bajo la plataforma inferior. Los aludes de finales de primavera, con las laderas liberadas de nieve, poseen pues, una elevada efectividad geomorfológica, modelando canales de aludes y generando conos de deyección mixtos de elevada velocidad de transferencia de sedimentos desde las plataformas al fondo del valle.

La permanencia del manto nival discontinuo y los neveros en las laderas más bajas, entre 0 y 100 metros, esta íntimamente ligada a los aludes de invierno y primavera, de modo que los neveros de fusión más tardía se localizan en las canales de aludes y en la salida de las mismas, sobre los conos y al pie de las laderas. El papel de los aludes en la redistribución de la nieve juega así un papel fundamental en la dinámica de las laderas, alargando los procesos nivales hasta junio en las porciones inferiores $(0-500 \mathrm{~m})$, y hasta mediados de julio en las medias (500-700 m).

\section{CONCLUSIONES}

En el Alto Ártico el manto nival presenta una estructura simple y, en general, poco potente, de modo que la topografía y los procesos de redistribución por el viento, dirigidos por el predominio de los vientos E-W que barren los fondos de valle, son los principales responsables de la complejidad y espesor de la nieve. Durante la estación fría la distribución de la nieve es regular y las diferencias de orientación norte sur, no son relevantes, debido a la importancia del viento y la ausencia continua en invierno o la presencia constante de luz solar y regular durante el verano. La transformación de la nieve deriva de los procesos de arrastre de nieve por el viento y del rehielo interno de las aguas de fusión, de modo que la dinámica y los procesos asociados al manto nival presentan dos periodos claramente diferenciados:

- Durante la estación fría, el manto nival es diferente en el fondo de valle y en las laderas. En el fondo del valle se caracteriza por una capa inferior estable de nieve endurecida por el viento, los procesos de rehielo y el icing, donde el permafrost posee 
un papel preponderante, y otra inestable de nieve sin cohesionar, venteada. En las laderas y depresiones (ventisqueros, cornisas e irregularidades a sotavento) la estructura es más compleja y se caracteriza por la presencia de estructuras tipo depth hoar (escarcha interna) y placas de viento. La nieve tiene una densidad baja derivada de las temperaturas muy frías y constantes que favorece su movilidad por el viento.

- En primavera, con la llegada de la radiación solar directa, la nieve inicia su transformación, poco antes de su desaparición. El manto nival se caracteriza por las costras de hielo o sun crust, las estructuras internas de rehielo, su densificación y transformaciones rápidas que propician movimientos en masa (aludes y slush de nieve). La presencia de permafrost frío $\left(<-4^{\circ} \mathrm{C}\right)$ favorece la lenta desaparición de la nieve. En primavera y verano el manto nival se desestabiliza y se produce una mayor frecuencia de aludes entre mayo y junio. Los aludes por desprendimientos de cornisas generan aludes de fondo de alta efectividad geomorfológica mediante la erosión y el transporte de materiales, modelando canales y conos de derrubios mixtos.

La desaparición del manto nival es rápida, con un promedio de 40 días para su desaparición total al nivel del mar, y 35 días a 700 metros. Los procesos periglaciares y nivales asociados a la fusión del manto nival se alargan durante 3 meses, de abril a junio, entre los 0-700 metros, y entre julio y agosto por encima de 700 metros, con un promedio de $250 \mathrm{~m} / \mathrm{mes}$ de ascenso en altitud. Este constituye el periodo morfogenético más eficaz, por la elevada disponibilidad hídrica en las laderas y fondos de valle, y los periodos de mayor gradiente térmico diurno-nocturno. Las variaciones del ritmo de fusión implican ritmos diferentes a distintas altitudes, con un periodo de fusión de dos meses por debajo de los 400 metros, donde las laderas se liberan antes del manto nival y se generan los procesos geomorfológicos más eficaces en un periodo de entre dos meses y dos meses y medio. A mayor altitud la fusión es más tardía pero el manto discontinuo desaparece más rápido, de modo que los procesos geomorfológicos se concentran en un periodo más breve. Por encima de 700-800 m no desaparece el manto nival discontinuo, perdurando neveros y cornisas durante todo el año. La gelifluxión, la crioclastia, la ordenación, el icing y los levantamientos por helada son los procesos asociados a la disponibilidad hídrica y al régimen térmico del suelo que funcionan escalonadamente en el tiempo y con la altitud en los valles estudiados. La transferencia de sedimentos mediante movimientos en masa, los aludes o las aguas de fusión, perduraran durante todo el periodo de desaparición del manto nival, derivado de las relaciones verticales que generan estos procesos.

Agradecimientos: a Wesley Farnsworth, geólogo y estudiante de la University of Svalbard (UNIS), por su compañía e inestimable ayuda durante los trabajos de campo de junio de 2010 en Reindalen. A la University of Svalbard (UNIS), por la información, el apoyo logístico y el equipamiento facilitado para la realización de los trabajos de campo en 2004 y 2010.

\section{BIBLIOGRAFÍA}

ANDRÉ, M.F. (1990a): «Frequency of debris flows and slush avalanches in Spitsbergen: a tentative evaluation from lichenometry». Polish Polar Research, 11, 345-363. 
ANDRÉ, M.F. (1990b): «Geomorphic impact of spring avalanches in northwest Spitsbergen $\left(79^{\circ} \mathrm{N}\right) »$. Permafrost and Periglacial Processes, 1, 97-110.

BINTANJA, R. (1998): "The contribution of snowdrift sublimation to the surface mass balance of Antarctica». Annals of Glaciology, 27, 251-257.

BOIKE, J., ROTH, K. y IPPISCH, O. (2003): «Seasonal snow cover on frozen ground: Energy balance calculations of a permafrost site near Ny-Ålesund, Spitsbergen». Journal of Geophysival Research, 108 (D2), 8163, doi: 10.1029/2001JD000939.

BRULAND, O. (2002): Dynamics of seasonal snowcover in the Arctic. PhD thesis, Norwegian University of Science and Technology, Trondheim.

BRULAND, O., SAND, K. y KILLINGTVEIT, Å. (2001a): «Snow Distribution at a High Arctic Site at Svalbard». Nordic Hydrology, 32 (1), 1-12.

BRULAND, O., MARÉCHAL, D., SAND, K. y KILLINGVEIT, Å. (2001b): «Energy and water balance studies of snow cover during snowmelt period at a High Artic site». Theoretical and Applied Climatology. 70, 53-63.

CHRISTIANSEN, H.H. (2001): «Snow-cover depth, distribution and duration data from northeast Greenland obtained by continuous automatic digital photography». Annals of Glaciology, 32, 102-108.

CHRISTIANSEN, H.H. y HUMLUM, O. (2008): «Interannual Variations in Active Layer Thickness in Svalbard». En DOUGLAS L. KANE y KENNETH M. HINKEL (Eds.): Proceedings of the Ninth International Conference on Permafrost, University of Alaska Fairbanks, Fairbanks, 257-262.

DALLMANN, W.K., KJÆRNET, T. y NOTTVEDT, A. (2001): «Geological map of Svalvard, 1/100.000. En Geological map of Svalvard and Geomorphological and Quaternary geological map of Svalbard. Norwegian Polar Institute, Temakart n $n^{\circ} 31 / 32$, Troms $\varnothing, 57-78$.

ECKERSTORFER, M. y CHRISTIANSEN, H.H. (2010): «High Arctic Avalanche Climate in Central Svalbard». Geophysical Research Abstracts, Vol. 12, EGU2010-5860.

ECKERSTORFER, M., CHRISTIANSEN, H.H. y HUMLUM, O. (2010): «High Arctic snow avalanche observations and modelling in Svalbard 2007-2009». Geophysical Research Abstracts, Vol. 12, EGU2010-3674.

ECKERSTORFER, M., NEUMANN, U. y CHRISTIANSEN, H.H. (2008): «High arctic avalanche monitoring in maritime Svalbard». En Proceedings of the International Snow Science Workshop 2008. Whistler, Canada, 784-791.

ELLEHAUGE, J. (2003): Influence of meteorological and topographic conditions on snow avalanches in Central Spitsbergen, Svalbard. Ms Thesis. UNIS, Longyearbyen, 65 pp.

EVANS, I.S. y COX. N. J. (2010): «Climatogenic north-south asymmetry of local glaciers in Spitsbergen and other parts of the Arctic». Annals of Glaciology, 51(55), 16-22.

FIERZ, C., ARMSTRONG, R.L., DURAND, Y., ETCHEVERS, P., GREENE, E., MCCLUNG, D.M., NISHIMURA, K., SATYAWALI, P.K. y SOKRATOV, S.A. (2009). The International Classification for Seasonal Snow on the Ground. IHP-VII Technical Documents in Hydrology $\mathrm{n}^{\circ}$ 83, IACS Contribution $\mathrm{N}^{\circ}$ 1, UNESCO-IHP, Paris.

GERLAND, S., WHINTER, J.G., ORBAEK, J.B., LISTON, G.E., ORITSAND, N.A., BLANCO, A. e IVANOV, B. (1999): «Physical and optical properties of snow covering Arctic tundra on Svalbard». Hydrological Processes, Vol. 13 (14/15), 2331-2343. 
GRZÉS, M. y SOBOTA, I. (2000): «Winter snow accumulation and discharge from Werenskiold glacier, Northwestern Spitsbergen in 1996-1998». Polish Polar Research, 21, 19-32.

HARDING, R. J. y LLOYD, C.R. (1998): «Fluxes of energy and water from three high latitude tundra sites in Svalbard during the snowmelt and snow free periods». Nordic Hydrology, 29 (4/5), 267-284.

HARLAND, H.B. (1997): The Geology of Svalbard. The Geological Society, Mem.19, Londres, $521 \mathrm{pp}$.

HESTNES, E. (2000): «Impact of rapid mass movement and drifting snow on the infrastructure and development of Longyearbyen, Svalbard». En Proceedings International Workshop on Permafrost Engineering, 259-282.

HUMLUM, O. (2002): «Modelling late 20th century precipitation in Nordenskiöld Land, central Spitsbergen, Svalbard, by geomorphic means». Norwegian Geographical Journal 56, 96-103.

HUMLUM, O. (2005a): «Modeling of Snow Avalanche Potential in Nordenskiöldland, Central Spitsbergen». Disponible en http://www.unis.no/studies/geology/ag_204_more_ info/ole.htm (consulta 28-12-2010).

HUMLUM, O. (2005b): «Svalbard Snow Avalanche advice». Disponible en: http://www. unis.no/studies/geology/ag_204_more_info/ole.htm. (consulta 28-12-2010).

HUMLUM, O. (2005c): «Holocene permafrost aggradation in Svalbard». En Harris, C. y Murton, J.B. (Eds). Cryospheric Systems: Glaciers and Permafrost. Geological Society, London, Special Publication, 242, 119-130.

HUMLUM, O., CHRISTIANSEN, H.H. y JULIUSSEN, H. (2007): «Avalanche-derived Rock Glaciers in Svalbard». Permafrost and Periglacial Processes. 18, 75-88.

HUMLUM, O., INSTANES, A. y SOLLID, J.L. (2003): «Permafrost in Svalbard: a review of research history, climatic background and engineering challenges». Polar Research, 22 (2), 191-215.

INSTANES, A., LØNNE, I. y SANDAKER, K. (2004): «Location of avalanche victims with ground-penetrating radar». Cold Regions Science and Technology 38, 55-61.

JAEDIKE, CH. y SÁNDVIK, A.D. (2002): «High resolution shows distribution data from complex Arctic terrain: a tool for model validation». Natural Hazards and Earth System Sciences, 2, 147-155.

LIESTØL, O. (1980): «Permafrost conditions in Spitzbergen». Frost I Jord, 21, 23-28.

LISTON, G.E. y STURM, M. (2002): «Winter precipitation patterns in arctic Alaska determined from a blowing-Snow model and snow-depth observations». Journal of Hydrometeorology, 3, 646-659.

MAJOR, H., DALLMANN, W.K., KÆRNET, T., NØTTVEDT, A., TOLGENSBAKK, J., SØRBEL, L. y HØGVARD, K. (2001): Geomorphological and Quaternary Geological Map of Svalbard 1:100.000. Troms $\varnothing$. Norsk Polarinstitutt, 78 pp.

MALE, D.H. (1980): «The Seasonal Snowcover». En COLBECK, S.C. (Ed.): Dynamics of Snow and Ice, Academic Press, London, 322-349.

MARTÍN MORENO, R. (2006): Estudio comparativo de formas y procesos glaciares y periglaciares. Altas latitudes noruegas y altas altitudes españolas. Tesis Doctoral. Universidad Autónoma de Madrid. Madrid, 705 pp. 
MING-KO WOO (1998): «Arctic snow cover information for hydrological investigations at various scales». Nordic Hydrology, 29 (4/5), 245-266.

POMEROY, J.W. y GRAY, D.M. (1990): «Saltation of snow». Water Resources Research, 26, 1583-1594.

RØNNING, O.I. (1996). The flora of Svalbard. Norsk Polar Institute, Oslo, 184 p.

RUBENSDOTTER L. y ECKERSTORFER, M. (2010). «Todalen periglacial slope processes including avalanches». En BERTHLING, I. (Ed.). Field guide for excursions, EUCOP III Svalbard. NGU Report n 2010.031, Norway, 108-116.

SAND, K., WINTHER, J.G., MARECHAL, D., BRULAND, O. y MELVOLD, K. (2003): «Regional variations of snow accumulation on Spitsbergen, Svalbard in 1997-99». Nordic Hydrology, 34, 17-32.

SCHMIDT, R.A. (1981): «Estimates of threshold windspeed from particle sizes in blowing snow». Cold regions science and technology, 4, 187-193.

SØRBEL, L., TOLGENSBAKK, J., HAGEN, J.O. y HOGVARD, K. (2001): «Geomorphological and Quaternary geological map of Svalbard, 1/100.000». En Geological map of Svalvard and Geomorphological and Quaternary geological map of Svalbard. Norwegian Polar Institute, Temakart no 31/32, Troms $\varnothing$, 4-55.

STURM, M., MCFADDEN, J., LISTON, G.E., STUART CHAPIN, F., RACINE, C.H. y HOLMGREN, J. (2001): «Snow-Shrub Interactions in Arctic Tundra: A Hypothesis with Climate Implications». Journal of Climate, 14, 336-343.

TOLGENSBAKK J., SØRBEL L. y HOGVARD K. (2001): Adventdalen, Geomorphological and Quaternary Geological map, Svalbard 1: 100,000, Spitsbergen sheet C9Q. Norsk Polarinstitutt Temakart $\mathrm{n}^{\circ} 32$. University of Science and Technology, Trondheim.

VILAPLANA, J.M. y PALLÁS, R. (1993): «Características y evolución del manto nivoso en la Isla de Livingston». En CACHO, J. y SERRAT, D. (Eds.): Actas del V Simposio de estudios antárticos. Comisión Interministerial de Ciencia y Tecnología, Madrid, 279-290.

WINTHER, J.-G., GERLAND, S., ØRBÆK, J.B., IVANOV, B., BLANCO, A. y BOIKE, J. (1999): «Spectral reflectance of melting snow in a high Arctic watershed on Svalbard: Some implications for optical satellite remote sensing studies». Hydrological Processes, 13, 2033-2049.

WINTHER, J.G., BRULAND, O., SAND, K., GERLAND, S., MARECHAL, D., IVANOV, B., GLOWACKI, P. y KÖNIG, M. (2003): «Snow research in Svalbard-an overview». Polar Research, 22, 2, 125-144.

WOO, M. K., MARSH, P. y STEER, P. (1983): «Basin water balance in a continuous permafrost environment». En Proceedings of the Fourth International Conference on Permafrost, Nat. Acad. Sci., Washington, D.C., 1407-1411.

YOUNG, K. L., M. K. WOO, y S. A. EDLUND, (1997): «Influence of local topography, soil and vegetation on microclimate and hydrology at a high Arctic site». Arctic and Alpine Research 29, 270-284. 